\title{
Further observations on clinical, histopathological, and immunological features of borderline disseminated cutaneous leishmaniasis caused by Leishmania (Leishmania) amazonensis
}

\author{
Fernando T Silveira/*/+ , Ralph Lainson, Carlos EP Corbett** \\ Departamento de Parasitologia, Instituto Evandro Chagas, Av. Almirante Barroso 492, 66090-000 Belém, PA, Brasil *Núcleo de \\ Medicina Tropical, Universidade Federal do Pará, Belém, PA, Brasil **Departamento de Patologia, Faculdade de Medicina, \\ Universidade de São Paulo, São Paulo, SP, Brasil
}

Leishmania (Leishmania) amazonensis has for some time been considered as the causative agent of two distinct forms of American cutaneous leishmaniasis (ACL): localized cutaneous leishmaniasis (LCL), and anergic diffuse cutaneous leishmaniasis (ADCL). Recently, a new intermediate form of disease, borderline disseminated cutaneous leishmaniasis $(B D C L)$, was introduced into the clinical spectrum of ACL caused by this parasite, and in this paper we record the clinical, histopathological, and immunological features of eight more BDCL patients from Brazilian Amazonia, who acquired the disease in the Pará state, North Brazil. Seven of them had infections of one to two years' evolution and presented with primary skin lesions and the occurrence of metastases at periods varying from six to 12 months following appearance of the first lesion. Primary skin lesions ranged from 1-3 in number, and all had the aspect of an erythematous, infiltrated plaque, variously located on the head, arms or legs. There was lymphatic dissemination of infection, with lymph node enlargement in seven of the cases, and the delayed hypersensitivity skintest (DTH) was negative in all eight patients prior to their treatment. After that, there was a conversion of DTH to positive in five cases re-examined. The major histopathological feature was a dermal mononuclear infiltration, with a predominance of heavily parasitized and vacuolated macrophages, together with lymphocytes and plasma cells. In one case, with similar histopathology, the patient had acquired his infection seven years previously and he presented with the largest number of disseminated cutaneous lesions. BDCL shows clinical and histopathological features which are different from those of both LCL and ADCL, and there is a good prognosis of cure - which is generally not so in the case of frank ADCL.

Key words: borderline disseminated cutaneous leishmaniasis - Leishmania (Leishmania) amazonensis - histopathology clinical manifestations - Brazil

Silva (1945) described the first reported case of anergic diffuse cutaneous leishmaniasis (ADCL) in Brazil and this strange form of American cutaneous leishmaniasis (ACL) was for long considered to be a clinical variety of infection with Leishmania braziliensis (Guimarães \& Costa 1966). Following studies on the morphology, biochemistry, and behavior of the parasite in laboratory animals and in vitro culture, however, Lainson and Shaw (1972) showed the parasite to be a member of the $L$. mexicana complex, named it Leishmania mexicana amazonensis and stressed its medical importance as the cause of ADCL, a virtually incurable form of ACL. In a subsequent revision of the classification of the neotropical leishmanias (Lainson \& Shaw 1987) they then named the organism as L. amazonensis, within the subgenus Leishmania.

Human infection with $L$. (L.) amazonensis is far less common than ACL due to parasites such as L. (Viannia) braziliensis and $L$. (V.) guyanensis, largely because the

Financial support: Secretaria de Vigilância em Saúde, Ministério da Saúde (FTS), the Wellcome Trust, London (RL)

+Corresponding author. E-mail: fernandotobias@iec.pa.gov.br Received 2 February 2005

Accepted 18 August 2005 principal sandfly vector, Lutzomyia flaviscutellata, is not very anthropophilic and essentially of nocturnal activity (Shaw et al. 1972, Ward et al. 1978, Lainson \& Shaw 1979, 1987, Shaw \& Lainson 1987). A substantial increase in the number of cases recorded in our laboratory during the past 15 years or so might be attributed to improved diagnosis by modern biochemical, serological and molecular biological methods, although there is little difficulty in identifying $L$. (L.) amazonensis following its exuberant development in the skin of the hamster and in simple bloodagar culture media. A more likely explanation is that drastic ecological changes in the forest environment have increased the type of habitat preferred by the vector and thrown this sand fly into closer contact with man (Lainson 1988).

For some time there was a general impression that $L$. (L.) amazonensis would cause only two distinct forms of ACL: either localized cutaneous leishmaniasis (LCL), represented in most cases by a single ulcerated skin lesion accompained by a high (> 50\%) prevalence of negative delayed hypersensitivity skin-test (DTH) in patients who are, nevertheless, cured by conventional antimonial therapy (Silveira et al. 1991, 1998), or the rare cases of ADCL characterized by a diffuse infiltration in the skin of the patients and a consistently negative DTH, resulting in a high resistence of this disease to any type of chemotherapy (Silveira et al. 1997, Lainson \& Shaw 1998). It has 
been demonstrated, however, that this species of Leishmania may also be the cause of an intermediate form of disease, borderline disseminated cutaneous leishmaniasis (BDCL), in which the dissemination of $L$. (L.) amazonensis is observed only after six months following the appearance of the primary cutaneous lesion, which has been represented in $100 \%$ of cases by an erythematous infiltrated plaque. The dissemination of infection has resulted, in most cases, in a limited number (six at a maximum) of secondary cutaneous lesions with the same characteristic of the primary one, within a period of one to two years of disease. Cases of BDCL have been accompanied by an intense, but incomplete, inhibition of the cell-mediated immune mechanisms of the patients, resulting in negative responses of the DTH as well as the lymphocyte proliferation assay, although the patient's cellular immune response had totally been restored with the conventional antimony therapy in all cases, which has prompted us to use the term borderline for this form of disease (Silveira et al. 2004). In this context, it is the subject of this paper to describe further observations on clinical, histopathologi$\mathrm{cal}$, and immunological features of BDCL, to discuss the pathology and evolution of the resulting lesions, and the treatment of these patients with the attempt of clarifying our understanding on the clinical spectrum of human infection with $L$. (L.) amazonensis. This could help us to avoid some mistaken regarding the diagnosis of clinical forms of ACL by this parasite species.

\section{MATERIALS AND METHODS}

Patients - Clinical examination and diagnosis of patients infected with $L$. (L.) amazonensis were all made in the leishmaniasis laboratory of the Evandro Chagas Institute in Belém, state of Pará, Brazil, with particular attention paid to the patient's occupation and the probable locality in which the disease was acquired, duration and evolution of the infection, the number and type of skin lesions, and their distribution on the body (Table).

Laboratory examinations - $a$ : for the detection of amastigotes, smears of exudates from the lesions were rapidly air-dried, fixed in absolute methyl alcohol and stained by Giemsa' method; $b$ : each patient was subjected to a Montenegro skin-test in order to evaluate his delayed hypersensitivity response to Leishmania antigen (Silveira et al. 1991); $c$ : punch biopsies were performed to provide material for isolation of the parasite following intradermal inoculation of triturated tissue into the feet of hamsters, and its cultivation in Difco B45 culture medium (Walton et al. 1977). A piece of each biopsy was fixed in neutral formalin solution (10\%, $\mathrm{pH} 7.2)$ and skin sections were stained by hematoxilin-eosin for histopathology; $d$ : enlarged subcutaneous lymph-nodes were excised from seven patients for the detection of parasites in Giemsastained smears, inoculation of this tissue in hamsters and its culture in blood-agar medium. One fragment was also formalin-fixed and stained by hematoxilin-eosin for histopathology.

Identification of parasites isolated from the patients - This was based on the morphology of amastigotes and promastigotes; behaviour of the parasites in the skin of hamsters and in vitro culture; comparison of the isoenzyme electrophoretic profiles of each isolate with those of the references strains of Leishmania species from the Amazon Region of Brazil (Miles et al. 1979, Lainson et al. 1982), and by the use of species-specific monoclonal antibodies against these species (Shaw et al. 1989, Hanham et al. 1991).

\section{RESULTS}

Clinical manifestations, treatment, and subsequent evolution of disease - Clinical aspects and the treatment of cases of BDCL in Brazil have till now been poorly documented, and for this reason we will consider each of our eight cases separately.

Case 1 - Male, aged 30, presenting with three primary lesions in the form of irregularly shaped erythematous infiltrated plaques on the left elbow, the right shoulder and the dorsal surface of the thorax, and measuring approximately 10,7 , and $5 \mathrm{~cm}$ in diameter, respectively. All lesions were with one and a half year's evolution. There were also infiltrated metastatic lesions of the ear lobules and the nose, which had appeared one year after the primary lesions (Fig. 1). In addition, lymphatic dissemination of infection was evidenced by the presence of five enlarged, hard, motile, and painless lymph-nodes, of about $1-1.5 \mathrm{~cm}$ in diameter. Two were localized in the internal face of the left forearm, and three had appeared in the cervical region. As the patient had not received any previous treatment, we opted for the use of intravenous meglumine antimoniate $\left(850 \mathrm{mg} / \mathrm{Sb}^{\mathrm{v}} /\right.$ daily, for 25 days), this being our usual treatment for uncomplicated cases of cutaneous leishmaniasis. Four series of such inoculations were given, at 10-day intervals, and after two months there was total regression of the cutaneous lesions and the lymph-nodes (Fig. 2). One year later, the patient was without relapse.

Case 2 - Male, aged 17, he had a primary skin lesion consisting of a rounded, erythematous infiltrated plaque of about $6 \mathrm{~cm}$ in diameter on the left elbow. Duration of this lesion was about one year. He also presented with six secondary skin lesions, mostly with a similar appearance: one was near the primary lesion, and had ulcerated, three were on the legs and one each on the thigh and the face. The evolution of these secondary lesions was about six months. In addition, the patient had eleven enlarged hard, motile and painless lymph-nodes of about $1-1.5 \mathrm{~cm}$ in diameter and located in the sub-mandibular (1) and cervical (2) regions, the elbow (3), the internal face of the left arm (3) and the dorsal surface of the right foot (2). Treatment of this patient with meglumine antimoniate $\left(425 \mathrm{mg} / \mathrm{Sb}^{\mathrm{v}} /\right.$ daily for 10 days) had failed, but we nevertheless decided to use the same scheme used for the first case. Unfortunately, this proved only partially efficient. So did three series of pentamidine isethionate $(4 \mathrm{mg} / \mathrm{kg} / 48 \mathrm{~h}$, series of five days), and three series of sodium stibogluconate (800 $\mathrm{mg} / \mathrm{Sb}^{\mathrm{v}} /$ daily for 25 days) with 10 day intervals between each series. We therefore resolved to try immunochemotherapy, using pentamidine isethionate associated with Leishvacin $^{\mathrm{R}}$ (Mayrink et al. 1979, 1985) and BCG vaccines (Convit et al. 1989), in an attempt to activate the patient's 
cell-mediated immune response (Silveira \& Mayrink 1993, 1997). After a series of five doses of pentamidine isethionate, the patient was vaccinated with a mixture of $0.5 \mathrm{ml}$ of Leishvacin ${ }^{\mathrm{R}}(500 \mu \mathrm{g}$ of nitrogen protein) and 0.1 $\mathrm{ml}$ of BCG. Inoculation was by the intradermal route, $0.2 \mathrm{ml}$ in each of three places of the deltoid region, and repeated 30 days later. After six months of the second dose there was total healing of the cutaneous lesions and at the present date (five years later) there has been no sign of relapse.

Case 3 - Male, aged 27, presenting with a primary skin lesion in the form of an erythematous, infiltrated plaque of about $20 \mathrm{~cm}$ in diameter, located on the dorsal surface of the right hand and the fist; duration of the disease was approximately one and half years. He had secondary, erythematous and infiltrated lesions on the ear lobules, nose and forehead, and which had appeared six months after the primary lesion. The patient also had two enlarged, hard, motile and painless lymph-nodes of about $1.5 \mathrm{~cm}$ diameter in the cervical region. Like the second patient, this man had also undergone unsuccessful treatment with meglumine antimoniate (425 mg/Sbv/daily for 20 days), and we likewise decided to change the therapy to pentamidine isethionate. Again, as this produced no significant improvement in the patient's condition, we reverted to the immunochemotherapy scheme used for Case 2, giving this on three occasions during a period one year. There followed complete cure of all lesions.

Case 4 - Male, aged 24, presenting with a primary skin lesion of one year's duration, in the form of an irregularly shaped erythematous, infiltrated plaque, $15 \mathrm{~cm}$ in diameter, and forming nodules on the right elbow. In addition, two smaller lesions measuring 3-4 cm in diameter and with the same characteristics, were present on the dorsal tho-
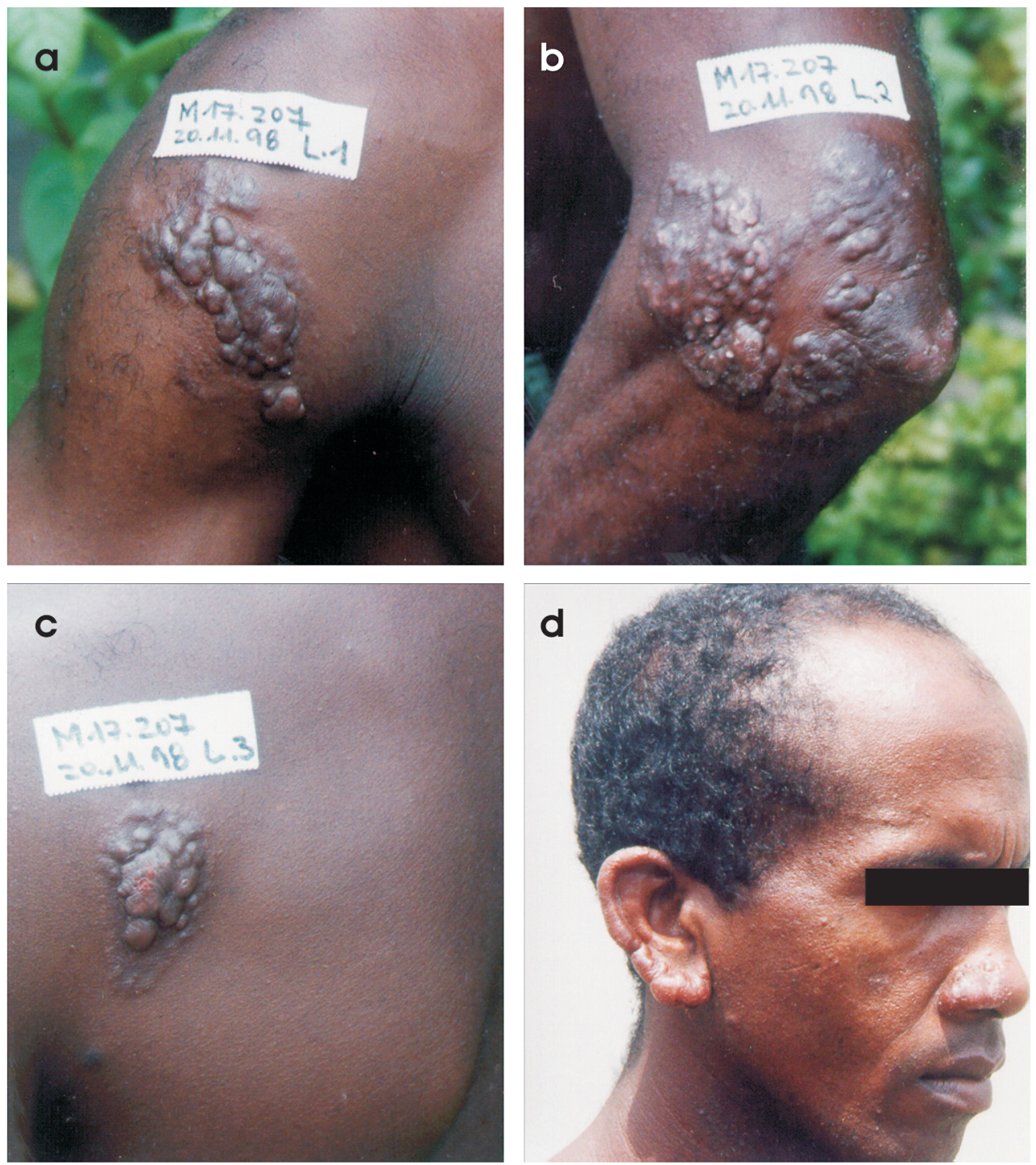

Fig. 1: a typical case of borderline disseminated cutaneous leishmaniasis caused by Leishmania (L.) amazonensis with 18 months of evolution. In the pictures (a), (b), and (c) the primary skin lesions are represented by erythematous infiltrated plaques on the right shoulder, the left elbow, and the dorsal surface of the thorax, respectively. In the picture (d), there are infiltrated secondary lesions, of one year evolution, on the right ear lobule and the right wing of the nose. 
rax and on the right thigh, respectively: these were estimated to be of approximately two months duration. Once again, lymphatic dissemination was evidenced by the presence of three enlarged lymph-nodes with characteristics similar to those of previous patients, measuring of about $1-1.5 \mathrm{~cm}$ in diameter, and detected in the right arm.

Case 5 - Male, aged 57, with a primary skin lesion of one year's evolution, forming an erythematous infiltrated plaque about $12 \mathrm{~cm}$ in diameter, located in the left lumbar region. In addition, six months following the appearance of the first lesion there had appeared two small, infiltrated metastatic lesions of 4 to $5 \mathrm{~cm}$ diameter and only $10 \mathrm{~cm}$ distant from the primary plaque. In contrast with the previous cases, this patient showed no detectable enlargement of lymph-nodes.

Case 6 - Male, aged 27. This individual had the longest history of infection. Seven years previously his condition was erroneously diagnosed as lepromatous leprosy, for which the result that he received specific treat- ment for that disease until examined in our laboratory. In spite of this long duration of the infection, three ulcerated primary lesions were recognized, on the left elbow, one fist and the right knee. They measured $4-5 \mathrm{~cm}$ at the largest diameter and their edges were surrounded by an intense infiltration. A dermal infiltration extended to a large part of the body, including the arms, legs, abdomen, thorax, face and ears. Some papules and nodules were apparent on the fingers and toes. Dissemination by the lymphatic route was indicated by the presence of five enlarged lymph-nodes: three in the internal surface of the left arm, and two in the right cervical region. They had the same characteristics as those described in other patients.

Case 7 - Male, aged 11, presenting with a primary skin lesion in the form of an erythematous plaque of $15 \mathrm{~cm}$ diameter on the left forearm. The infection was of one and a half year's duration. A secondary, infiltrated lesion of $2.5 \mathrm{~cm}$ diameter had appeared one year after the first, and was located on the right side of the boy's face. Two en-
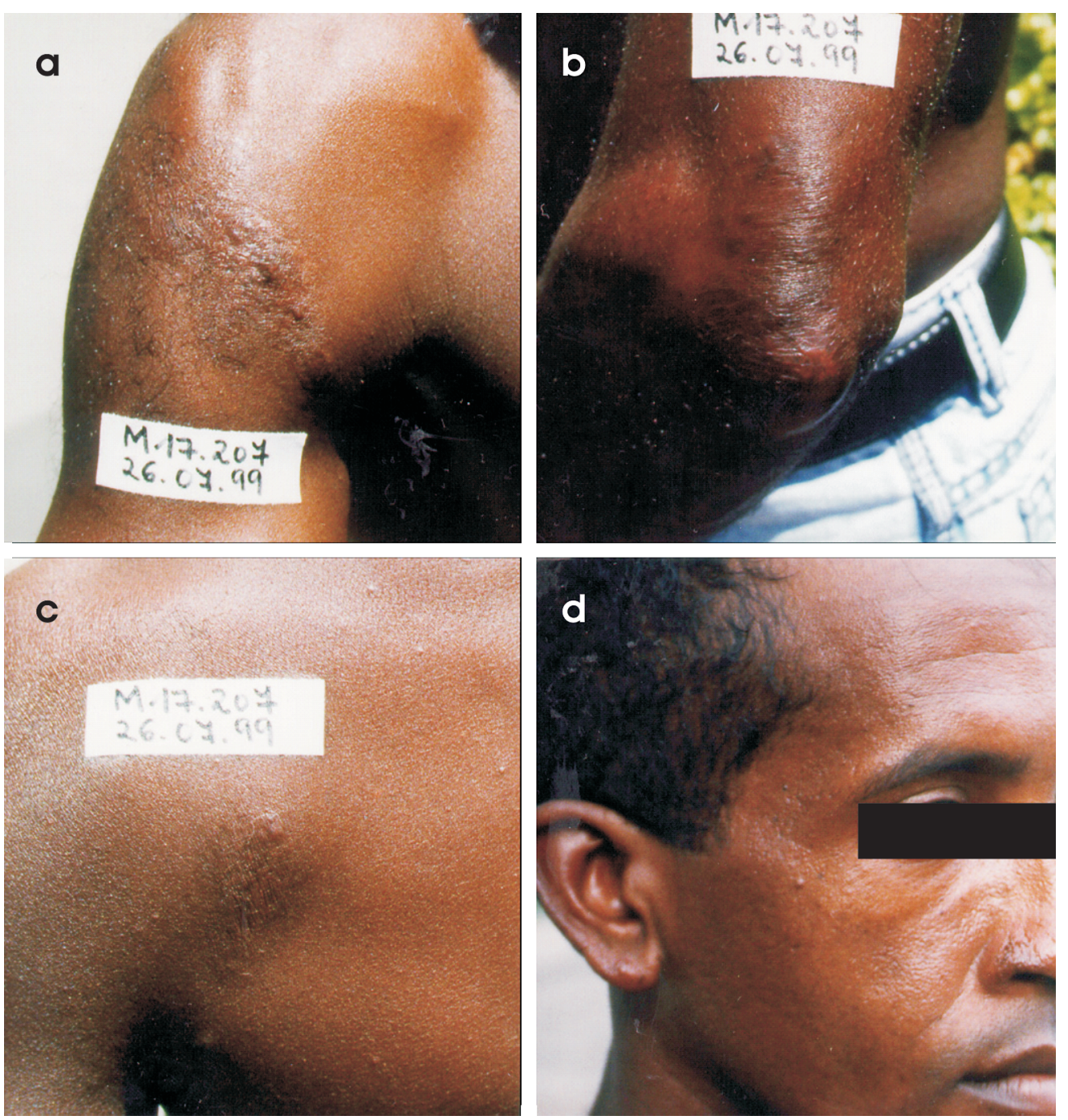

Fig. 2: the same patient seen in Fig. 1, two months after four series of treatment with intravenous meglumine antimoniate $(850 \mathrm{mg} / \mathrm{Sbv} /$ daily, for 25 days). In the pictures (a), (b), and (c) there is total regression of the primary cutaneous lesions and, in the picture (d), the secondary cutaneous lesions. 
larged lymph-nodes of about $1 \mathrm{~cm}$ diameter and with features similar to those of the other patients, were palpated in the region of the left armpit.

Case 8 - Male, aged 42, presenting with a primary skin lesion, of one year's duration, as an erythematous infiltrated plaque of about $7 \mathrm{~cm}$ diameter on the right forearm. In addition, three secondary lesions of $1.5 \mathrm{~cm}$ diameter and with an infiltrated aspect could be recognized in the last two months of his infection: two of these were at the border of the primary lesion and one was on the right elbow. Lymphatic dissemination of infection was demonstrated by the presence of three enlarged lymph-nodes, each of $1 \mathrm{~cm}$ in diameter, with the same characteristics of the other cases, and located in the internal face of the right arm.

Cases 4, 5, 6, 7, and 8 - As none of these patients had received previous specific treatment for leishmaniasis, we used meglumine antimoniate and, with the exception of Case 7 (the 11-year old boy), followed the scheme outlined for Case 1. Case 4 received four series of injections, Cases 5 and 8 three, and Case 6 (with the longest duration of the disease) five series. Case 7 received four series of treatment, but with half of the dose $(425 \mathrm{mg}$ ) given to the adults. All of these patients were considered clinically cured, one year after this treatment and have shown no signs of relapse.

Laboratory diagnosis - Amastigotes were demonstrated in the lesions of all patients, and at least two isolations were made from each case: one from the primary lesion and another from a secondary lesion. All isolations were identified as $L$. (L.) amazonensis. The Montenegro skin test (DTH) was negative in all patients prior to treatment, with conversion to positive for all those we were able to repeat (Cases 2, 3, 4,5, and 8) after treatment. The parasitological examination of lymph nodes from seven patients with lymphatic dissemination of infection confirmed the presence of $L$. (L.) amazonensis by Giemsastained smears, in culture medium Difco B45 and by inoculation of hamsters.

Histopathology of skin biopsies - As this is of great importance in characterizing BDCL, we describe this separately for those cases that had no treatment prior to that given in our laboratory (Cases 1, 4, 5, 6, 7, and 8, with emphasis on Case 1), followed by that seen in cases who had received previous (unsuccessful) chemotherapy (Cases 2 and 3).

Case 1 - In sections of the first biopsy (before treatment commenced) the dermal lesion was formed by a dense cellular infiltrate, composed mainly of parasitized, vacuolated macrophages, among which were scattered a number of lymphocytes and plasma cells (Fig. 3). In the second biopsy, made after the first series of antimony treatment, the aspect was very different, with a focal invasion of the initial macrophage infiltrate by lymphocytes and plasma cells: there were notably less infected macrophages (Fig. 4a). In sections of the third biopsy, after the second course of treatment, the lymphocyte and plasma cell infiltrate was substantially less dense than that in the second biopsy, and there were some eosinophilic granules which possibly represented cellular and parasitic débris. Bundles of collagen appeared around this reaction, forming scars (Fig. 4b). The fourth biopsy, made after the third course of treatment, showed a more intense production of connective tissue which reached the superior dermis: the areas of lymphocytes and plasma cells infiltrate appeared as small isolated nodules.

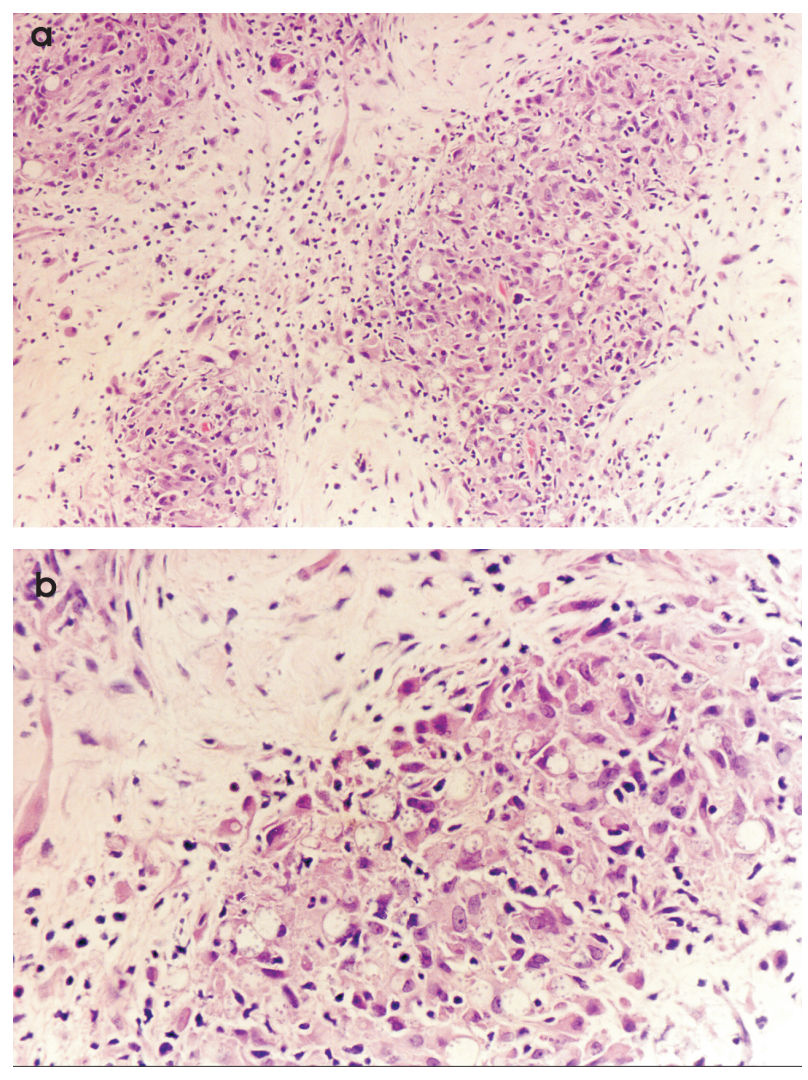

Fig. 3: typical histopathology of a borderline disseminated cutaneous leishmaniasis patient with infection caused by Leishmania $(L$.) amazonensis, before treatment. There is a dense mononuclear infiltrate in the dermis, composed mainly of parasitized, vacuolated macrophages, among which there are groups of lymphocytes and plasma cells in the middle of the infiltrate. H \& E, (a) $(\times 200)$, (b) $(\times 400)$.

Cases 4, 5, 6, 7, and 8 - The histopathology in sections of the biopsies of each case was very similar to that of Case 1. An exception was that of Case 6, the patient with the seven year-old infection, and he showed the heaviest infection of macrophages in the dermal cellular infiltrate. These infected cells were sometimes grouped in large collections, with an accumulation of lymphocytes and plasma cells scattered among them, or surrounding them.

Case 2 - Four biopsies were obtained from this patient, who had received prior and unsuccessful antimony treatment: two were from the primary lesion and two from a secondary one, before and after our own antimony treatment. The biopsies made from the primary and secondary 

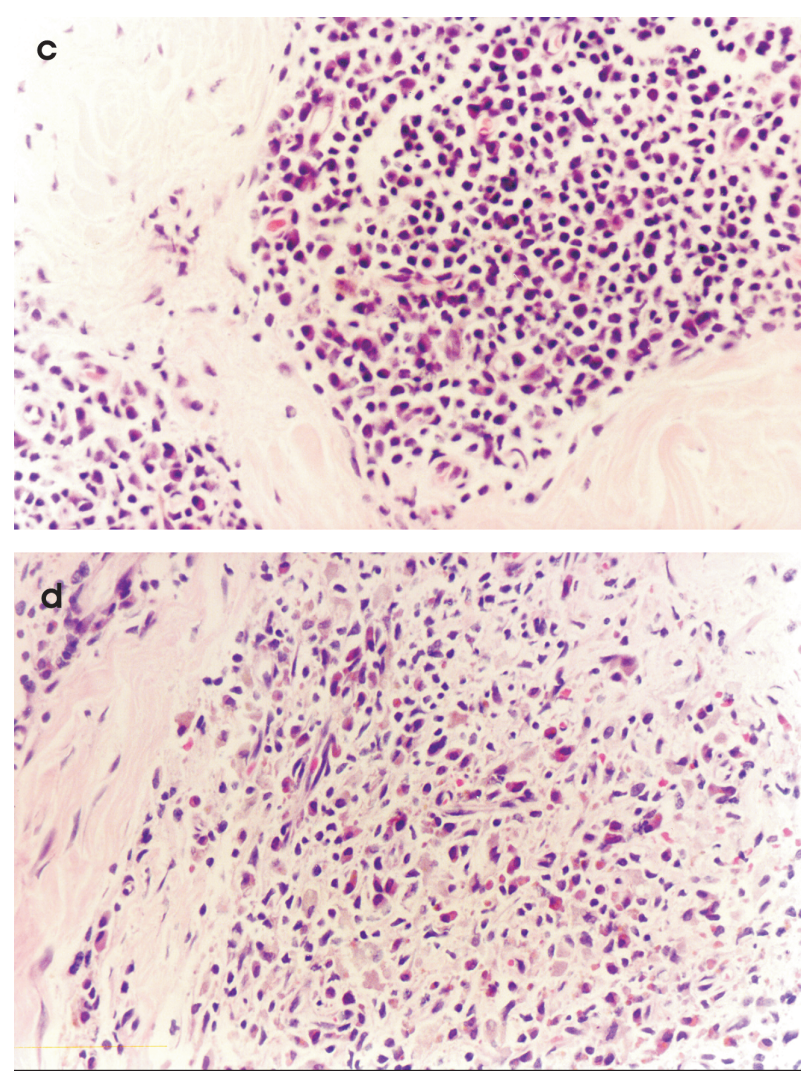

Fig. 4: the biopsy sequence of the borderline disseminated cutaneous leishmaniasis patient shown in Fig. 3. (c) $(\times 400)$. After the first series of antimony therapy, there is a focal invasion of the initial macrophage infiltrate by lymphocytes and plasma cells, with notably less infected macrophages inside the infiltrate $(d)(\times 400)$. After the second series of antimony therapy, the lymphocyte and plasma cells infiltrate was substantially less dense that in the previous biopsy, in which there are some eosinophilic granules which possibly represented cellular and parasitic débris. Bundles of collagen appear around the cellular infiltrate.

lesions before our treatment showed a very similar picture. This differed from that seen in Case 1 (patient with no previous treatment), however, almost certainly due to the patient's previous antimony chemotherapy. In the dermis there were large collections of parasitized macrophages, surrounded by a marked lymphocyte infiltrate together with a smaller number of plasma cells. In the subsequent biopsies, after our first antimony course of injections, the cellular infiltrate was enclosed by a fibrous tissue forming areas with granuloma, and in which could be seen giant and epithelioid cells, parasitized macrophages and lymphocytes.

Case 3 - For this patient, who had also experienced previous, unsuccessful meglumine antimoniate treatment, we were able to obtain only one biopsy, which was made from the primary lesion, before treatment in our laboratory. The histopathology was similar to that seen in Case 2 , after his first course of antimony therapy. The dermis showed a nodular and granuloma-like mononuclear infiltrate, mainly of lymphocytes and plasma cells, and con- taining a small number of parasitized macrophages: bundles of collagen surrounded the infiltrate.

Histopathology of lymph nodes - In general this showed collections of vacuolated macrophages containing a moderate number of amastigotes, surrounded and invaded by lymphocytes and plasma cells. In some nodes the cellular infiltrate was of a nodular form containing the same elements.

\section{DISCUSSION}

As we formerly referred, one of the aims of this work on the presentation of the further observations on clinical, histopathological and immunological features of BDCL by $L$. (L.) amazonensis was to try clarifying our understanding on the clinical spectrum of human infection with this species of Leishmania to avoid some mistaken on the interpretation of the clinical manifestations of ACL. In this way, we could not omit the considerable misuse with the term anergic diffuse cutaneous leishmaniasis (ADCL). Thus, Rodriguez et al. (1985) used it when describing the treatment of two patients with localized lesions. These were readily cured by thermotherapy and conventional meglumine antimony treatment, respectively, and there was no evidence of dissemination of the parasite. What led these authors to use this term was doubtless the negative Montenegro skin-tests of both patients together with a histopathology of the lesions showing an infiltrate composed principally of highly vacuolated macrophages containing abundant amastigotes. In the light of our present observations we would have referred to such infections as localized cutaneous leishmaniasis (LCL) (Moraes \& Silveira 1994, Silveira et al. 2004). Indications that some cases of cutaneous leishmaniasis due to $L$. (L.) amazonensis did not fit neatly into the categories of localized cutaneous leishmaniasis and anergic diffuse cutaneous leishmaniasis were noted by Lainson et al. (1986) and Silveira et al. (1991).

Considering that BDCL is an intermediate form of disease between LCL and ADCL, and that the term borderline was used to try characterizing the ambiguous nature of the cellular immune response in this form of ACL, sometimes resembling with LCL and in other occasions with ADCL, it seems reasonable to look for its clinical range. Thus, comparing our cases of BDCL with those of frank ADCL we note the following differences. In ADCL, evolution and dissemination of the infection is relatively rapid, with a very large number of nodular lesions which may be scattered all over the body, suggesting that in ADCL there is a minimal cell-mediated immune response of the patients against the infection by $L$. (L.) amazonensis. On other hand, in seven of our patients with BDCL the duration of infection was between 1-2 years, the number of lesions was low (3-7), and they were consistently in the form of erythematous infiltrated plaques rather than the characteristic nodules of ADCL. Our Case 6 was exceptional, in that his seven years of untreated infection had permitted a far more extensive dissemination of cutaneous lesions. Another difference that should be mentioned, concerns the age of patients, since most $(58.3 \%)$ of our twelve ADCL cases acquired their disease when they 
were less than five years old (Silveira, unpublished observations), while in the eight BDCL patients described here the great majority (87.5\%) of infections was acquired when they were older than 17 years old. The youngest BDCL patient was a 11 years boy (Table). These observations suggest that children below the age of five years may have a higher risk for developing ADCL when infected by $L$. (L.) amazonensis.

The lymphatic spread of infection detected by the enlarged, infected lymph-nodes in seven of our eight patients, either regional or some distance from primary lesions, appears to be an important aspect that is peculiar to BDCL, and we have not observed this in over 60 cases of LCL due to $L$. (L.) amazonensis (Silveira et al. 1991, Moraes \& Silveira 1994), or in all of twelve cases of frank ADCL (Silveira, unpublished observations). In the same way, no evidence of lymphatic dissemination was found in six cases of ADCL in the state of Maranhão, Brazil (Costa et al. 1992) and patients with ADCL due to parasites of the mexicana complex in Venezuela (Convit et al. 1972), Mexico (Velasco et al. 1989) and Peru (Franke et al. 1990). Whether or not this tendency of the infection to spread by way of the lymphatic system in cases of BDCL is related to biological and/or antigenic variation among isolates of $L$. (L.) amazonensis is debatable, but antigenic variation among isolates of $L$. (L.) aethiopica causing LCL and ADCL in Ethiopia has been recorded (Akuffo et al. 1987, 1988). In this context, it should be emphasized that $L$. (L.) amazonensis isolates from BDCL cases in Brazil have shown a higher infection index to peritoneal macrophages of $\mathrm{BALB} / \mathrm{c}$ mice than those isolates from LCL cases, but a smaller infection index than those isolates from ADCL cases. These observations strongly suggest that the spectrum of clinical manifestations of infection caused by $L$. (L.) amazonensis may be influenced by an intra-specific antigenic variation within $L$. (L.) amazonensis parasites (Gomes et al. 2002, 2003).

Our patients 1, and 4-8 (all biopsied prior to treatment) clearly give us the basic histopathological picture of BDCL due to $L$. (L.) amazonensis in the untreated patient, and we have used these in the following summary of the differences between this form of the disease and ADCL. Cases 2 and 3, who had unsuccessful treatment prior to our biopsies, clearly showed a modification of this picture, doubtless due to this chemotherapy.

The lesions of ADCL and BDCL do have one feature in common, namely the presence of highly vacuolated macrophages containing abundant amastigotes. In ADCL, however, the parasite burden is far greater than that seen in BDCL, and invasion of the infiltrate by lymphocytes and plasma cells is rarely seen. In contrast, all of our BDCL patients showed a notable invasion of the lesions by these cells and, approximately 30 days after iniciation of treatment, the macrophage reaction was superceded by a nodular lymphocyte and plasma cell infiltrate. As treatment continued, this intensified even further, to produce a fibrous tissue. This suggested that with adequate treatment the cell-mediated immune response of BDCL cases can be restored, with elimination of the infection and conversion of the Montenegro skin-test to positive: this was in fact achieved in all of our patients by conventional

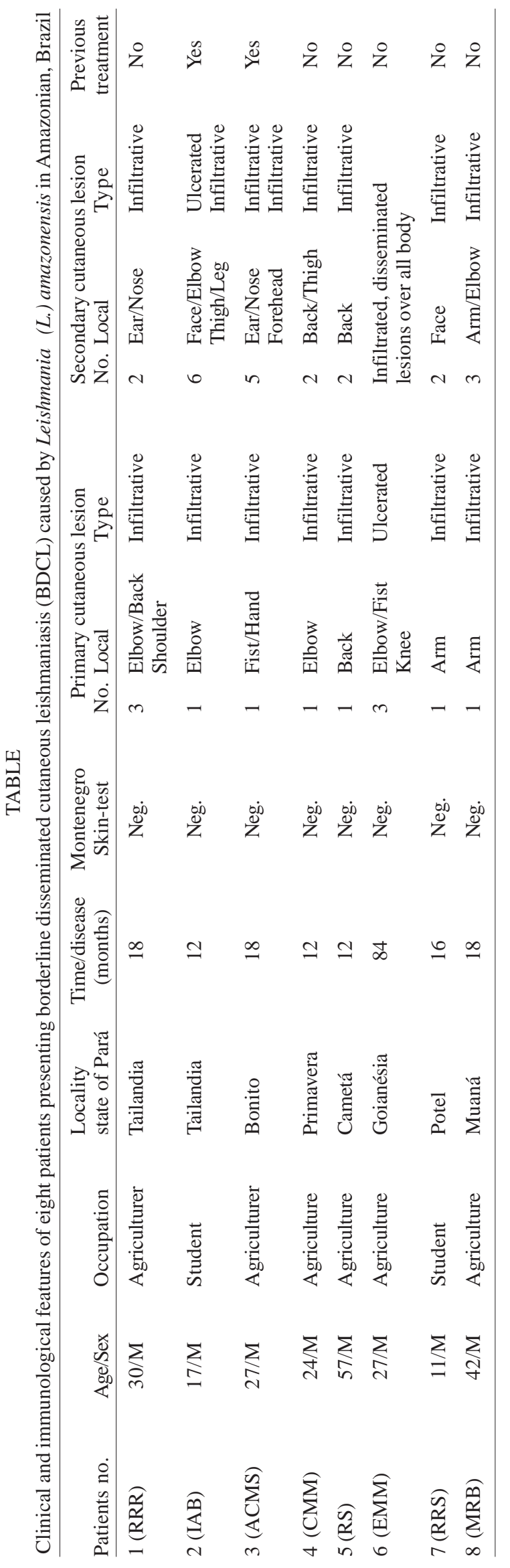


chemotherapy or, in the more difficult patients (Cases 2 and 3), by immunochemotherapy. Unhappily such results are seldom, if ever, achieved in cases of advanced ADCL. Our two patients who have received antimony treatment prior to examination in our laboratory showed an interesting variation in the evolution of their lesions, almost certainly due to differences in the dose of meglumine antimoniate given. Case 2, who had received only $10 \mathrm{am}-$ poules for each of six series of treatment, showed invasion of the lesion infiltrate by lymphocytes and plasma cells, but infected macrophages were still abundant. The biopsy of Case 3, who had taken a full 20 ampoules (425 $\mathrm{mg} / \mathrm{Sb}^{\mathrm{v}} /$ daily) in his six courses of treatment, showed the lesion to be with substantially more advanced signs of cure. The infiltrate already had a nodular, granuloma aspect, composed of lymphocytes, plasma cells and fewer infected macrophages, some of which appeared to be degenerating. A similar stage was reached in the biopsy of Case 2 made after we had initiated treatment.

The absence of a delayed hypersensitivity cellular reaction (Montenegro skin-test) is a well know feature of ADCL. What is less appreciated, however, is that over $50 \%$ of cases of simple, readily curable cases of LCL due to $L$. (L.) amazonensis may also be negative for this test, even when the infection is of 10-12 months duration (Lainson et al. 1986, Silveira et al. 1991). It would seem that, in some as yet unknown manner, this parasite and some other parasites of the subgenus Leishmania, are capable of at least partially inhibiting the cell-mediated immune response of the host. Finally, however, following conventional antimony treatment, or a combination of this and immunochemotherapy, there may be restoration of the cell-mediated immune mechanisms, cure, and a conversion to a positive Montenegro skin-test. In this respect it is of interest that Giorgio et al. (1992) found an inhibition of the lymphocyte proliferative response of BALB/c and C57BL/6 mice caused by a glycosphingolipid antigen isolated from the cell membrane of amastigotes of L. (L.) amazonensis. It is possibly that this molecular antigen may play a crucial role in modulation of the antigenspecific activation of the $\mathrm{CD}^{+}(\mathrm{Th} 1 / \mathrm{Th} 2)$ and $\mathrm{CD} 8^{+} \mathrm{im}-$ mune responses of the host.

Cases of disseminated cutaneous leishmaniasis caused by $L$. (L.) amazonensis have previously been described from the state of Bahia, Brazil, in two occasions by Costa et al. (1986) and Carvalho et al. (1994), respectively, but although these authors have demonstrated some inhibition of the cell-mediated immune mechanisms (DTH and lymphocyte proliferation assay) in most of their patients, they did not make any correlation of these immunological features with those seen in LCL and ADCL forms of disease, as well as they did not consider these cases as an intermediate form of ACL.

The term "borderline" cutaneous leishmaniasis was first used in Brazil in the description of an unusual case of infection with $L$. (V.) braziliensis, in the state of Bahia, by Moriearty et al. (1978). The patient, from a region with high incidence of mucocutaneous leishmaniasis, presented with multiple nodules and papules of the face, arms, and thorax, in addition to ulcerated lesions of the legs and feet, and a granulomatous lesion of the nasal mucosa.
Probably, what led to the definition of the term borderline, was the patient's inability to develop a positive Montenegro skin-test to leishmanial antigen. In our opinion this case was a typical example of borderline disseminated cutaneous leishmaniasis due to $L$. (V.) braziliensis, with a very recent compromising of the nasal mucosa tissue; in other words, a case with disseminated cutaneous infection due to $L$. (V.) braziliensis, and who was incapable of developing a cell-mediated immune mechanism (i.e. a positive DTH) against the parasite. He was at the stage of converting to a case of mucocutaneous leishmaniasis (MCL). This was the basis for our definition of borderline disseminated cutaneous leishmaniasis: either caused by L. (V.) braziliensis or other species within the subgenus Viannia, with development to the cellular hypersensitivity pole MCL, or caused by $L$. (L.) amazonensis and some other species within the subgenus Leishmania, which might evolve to the cellular hyposensitivity pole ADCL (Silveira et al. 2004).

\section{ACKNOWLEDGMENTS}

To Dr EAI Ishikawa for the identification of parasites isolated from the patients examined in this work by the monoclonal antibodies and the isoenzyme electrophoresis techniques.

\section{REFERENCES}

Akuffo H, Fehniger TE, Britton S 1988. Differencial recognition of Leishmania aethiopica antigens by lymphocytes from patients with local and diffuse cutaneous leishmaniasis. J Immunol 141: 2461-2466.

Akuffo HO, Shurr E, Anderson G, Yamanekerhan T, Britton S 1987. Responsiveness in diffuse versus local cutaneous leishmaniasis is due to parasite differences. Scand J Immunol 26: 717-721.

Bryceson ADM 1969. Diffuse cutaneous leishmaniasis in Ethiopia. I. The clinical and histological features of the disease. Trans R Soc Trop Med Hyg 63: 708-737.

Barral A, Costa JML, Bittencourt AL, Barral-Neto M, Carvalho EM 1995. Polar and subpolar diffuse cutaneous leishmaniasis in Brazil: clinical and immunopathologic aspects. Int J Dermatol 34: 474-479.

Bittencourt AL, Barral A, Costa J ML, Saldanha AC, Badaró F, Barral-Neto M, Freitas LAR 1992. Diffuse cutaneous leishmaniasis with atypical aspects. Int J Dermatol 31: 568570.

Carvalho EM, Barral A, Costa JML, Bittencourt A, Marsden PD 1994. Clinical and immunopathological aspects of disseminated cutaneous leishmaniasis. Acta Trop 56: 315-325.

Convit J, Castelanos PF, Ulrich M, Cástes M, Rondon A, Pinardi ME, Rodriguez N, Bloom BR, Formica S, Valecilos L, Bretana A 1989. Immunotherapy of localized, intermediate and diffuse forms of American cutaneous leishmaniasis. J Infec Dis 160: 104-115.

Convit J, Pinardi ME, Rondon AJ 1972. Diffuse cutaneous leishmaniasis: a disease due to an immunological defect of the host. Trans R Soc Trop Med Hyg 66: 603-610.

Costa JML, Marsden PD, Llanos-Cuentas EA, Netto EM, Carvalho EM, Barral A, Rosa AC, Cuba CC, Magalhães AV, Barreto AC 1986. Disseminated cutaneous leishmaniasis in a field clinic in Bahia, Brazil: a report of eight cases. Am J 
Trop Med Hyg 89: 319-321.

Costa JML, Saldanha ACR, Silva AMS, Neto AS, Galvão, CES, Silva, C de MP 1992. Estado atual da leishmaniose cutânea difusa (LCD) no Estado do Maranhão: II. Aspectos epidemiológicos, clínico-evolutivos. Rev Soc Bras Med Trop 25: 115-123.

Franke ED, Lucas CM, Tovar AA, Kruger JH, de Rivera MVS, Wignall FS 1990. Diffuse cutaneous leishmaniasis acquired in Peru. Am J Trop Med Hyg 43: 260-262.

Giorgio S, Jasiulionis MG, Straus AH, Takahashi HK, Barbieri CL 1992. Inhibition of mouse lymphocyte proliferative response by glycosphingolipid from Leishmania (L.) amazonensis. Exp Parasitol 75: 119-125.

Gomes CMC, Silveira FT, Cupollilo E, Costa JML, Braim L, Corbett CEP 2002. Análise genética de cepas de Leishmania (Leishmania) amazonensis e sua correlação com as diferentes formas clínicas de leishmaniose tegumentar americana. Rev Soc Bras Med Trop 35 (Supl. I): 323.

Gomes CMC, Silveira FT, Laurenti MD, Costa JML, Tomokane TY, Souza MGT, Corbett CEP 2003. Biological behavior of Leishmania (Leishmania) amazonensis isolated from different clinical forms of American tegumentar leishmaniasis in Balb/c mice. Rev Inst Med Trop São Paulo 45 (Supl. 13): 65.

Guimarães FN, Costa O 1966. Novas observações sobre a Leishmania isolada de "Oryzomys goeldi" na Amazônia (4 nota). Hospital 69: 161-168.

Hanham CA, Zhoa P, Shaw JJ, Lainson R 1991. Monoclonal antibodies for the identification of New Wolrd Leishmania. Trans R Soc Trop Med Hyg 85: 220-226.

Lainson R 1988. Ecological interactions in the transmission of the leishmaniases. Philos Trans R Soc Lond B Biol Sci 321 : 389-404.

Lainson R, Shaw JJ 1972. Leishmaniasis of the New World: taxonomic problems. Brit Med Bull 28: 44-48.

Lainson R, Shaw JJ 1979. The role of animals in the epidemiology of South American Leishmaniasis. In WHR Lumsden, DA Evans (eds), Biology of the Kinetoplastidae, Vol. 2, Academic Press, London, New York, San Francisco, p. 1-116.

Lainson R, Shaw JJ 1987. Evolution, classification and geographical distribution. In W Peters, R Killick-Kendrick (eds), The Leishmaniases in Biology and Medicine, Vol. 1, Academic Press, London, p. 1-120.

Lainson R, Shaw JJ 1998. New World Leishmaniasis - The Neotropical Leishmania species. In FEG Cox, JP Kreier, D Wakelin (eds), Topley \& Wilson's Microbiology and Microbial Infections, 9th ed., Vol. 5 Parasitology, Arnold, London, p. 242-266.

Lainson R, Shaw JJ, Miles MA, Póvoa MM 1982. Leishmaniasis in Brazil: XVII enzymic characterisation of a Leishmania from the armadillo, Dasypus novemcinctus (Edentata), from Pará State. Trans R Soc Trop Med Hyg 76: 611-612.

Lainson R, Shaw JJ, Silveira FT, Braga RR, Ryan L, Póvoa MM, Ishikawa EA 1986. A Leishmania e as leishmanioses. In Instituto Evandro Chagas; 50 Anos de Contribuição às Ciências Biológicas e à Medicina Tropical, Fundação Serviços de Saúde Pública, Belém, p. 83-124.

Maruno M, Taher RS, Khaskhely NM, Hagiwarw K, Hosokawa
A, Uezato H, Nonaka S, Gomez LEA, Hashiguchi Y 1997. Light microscopic and electron microscopic study on patients with cutaneous leishmaniasis treated with mephloquine. Japan J Trop Med Hyg 25: 44-52.

Mayrink W, Costa CA, Magalhães PA, Melo MN, Dias M, Oliveira Lima A, Michalick MS, Williams P 1979. A field trial of a vaccine against American dermal leishmanisis. Trans $R$ Soc Trop Med Hyg 73: 385-387.

Mayrink W, Williams P, Costa CA, Magalhães PA, Melo MN, Dias M, Oliveira Lima A, Michalick MSM, Carvalho EF, Barros GC, Sessa PA, Alencar TA 1985. Experimental vaccine against American dermal leishmaniasis: experience in the state of Espírito Santo, Brazil. Ann Trop Med Parasitol 79: 259-269.

Miles MA, Póvoa MM, de Souza AA, Lainson R, Shaw JJ 1979. Some methods for the enzymic characterization of Latin-American Leishmania with particular reference to Leishmania mexicana amazonensis and subspecies of Leishmania hertigi. Trans $R$ Soc Trop Med Hyg 74: 243-252.

Moraes MAP, Silveira FT 1994. Histopatologia da forma localizada de leishmaniose cutânea por Leishmania (Leishmania) amazonensis. Rev Inst Med Trop São Paulo 36: 459-463.

Moriearty PL, Bittencourt AL, Pereira C, Teixeira R, Barreto E, Guimarães NA 1978. Borderline cutaneous leishmaniasis: clinical, immunological and histological differences from mucocutaneous leishmaniasis. Rev Inst Med Trop São Paulo 20: $15-21$.

Nascimento MDSB, Alcantara-Neves NM, Muniz MEB, Nunes SF, Paranhos M, de Carvalho LCP 1993. Induction and modulation of the immune response to Leishmania by Montenegro skin test. Trans R Soc Trop Med Hyg 87: 9193.

Rodriguez G, Corredor A, Caceres E, Cassiano G, Arroyo C, Palau MT, Boshell J 1985. Leishmaniasis difusa. Biomédica 5: 95-111.

Shaw JJ, Lainson R 1987. Ecology and epidemiology: New World. In W Peters, R Killick-Kendrick (eds), The Leishmaniases in Biology and Medicine, Vol. 1, Academic Press, London, p. 291-363.

Shaw JJ, Ishikawa EAY, Lainson R 1989. A rapid and sensitive method for the identification of Leishmania with monoclonal antibodies using fluoroscein-labelled avidin. Trans $R$ Soc Trop Med Hyg 83: 783-784.

Shaw JJ, Lainson R, McMahon-Pratt D, David JR 1986. Serodemos of the Leishmania braziliensis complex. In Leishmania, Taxonomie et Phylogenèse. Applications écoépidémiologiques, Coll. int., CNRS/INSERM/OMS (July 2-6, 1984), IMEEE, Montpellier, France, p. 179-183.

Shaw JJ, Lainson R, Ward R 1972. Leishmaniasis in Brazil: VII. Further observations on the feeding habitats of Lutzomyia flaviscutellata (Mangabeira) with particular reference to its biting habits at different heights. Trans $R$ Soc Trop Med Hyg 66: 718-723.

Silva F 1945. Forma raríssima de leishmaniose tegumentar: leishmaniose dérmica não ulcerada em nódulos e extensas placas infiltradas e hiperpigmentadas. An Bras Soc DérmatoSifilógrafos 1: 97-99.

Silveira FT, Mayrink W 1993. Leishmaniose cutânea anérgica 
difusa no Estado do Pará, Brasil: Registro do primeiro caso de cura da doença, após associação de quimioterapia com imunoterapia. XXIX Congresso da Sociedade Brasileira de Medicina Tropical, Fortaleza, Estado do Ceará, Brasil, tema livre 313, pp. 229.

Silveira FT, Mayrink W 1997. Leishmaniose cutânea anérgica difusa no Estado do Pará, Brasil: Relato da cura de um caso depois de 24 anos de doença, após tratamento combinado de quimioterapia com imunoterapia. XXXIII Congresso da Sociedade Brasileira de Medicina Tropical, Belo Horizonte, MG, Brasil, poster 42, p. 129.

Silveira FT, Blackwell JM, Ishikawa EA, Braga RR, Shaw JJ, Quinnell RJ, Soong L, Kima P, McMahon-Pratt D, Black GF, Shaw M-A 1998. T cell responses to crude and defined leishmanial antigens in patients from the lower Amazon region of Brazil infected with different species of Leishmania of the subgenera Leishmania and Viannia. Parasite Immunol 20: 19-26.

Silveira FT, Lainson R, Corbett CEP 2004. Clinical and immunopathological spectrum of American cutaneous leishmaniasis with special reference to the disease in Amazonian Brazil - A review. Mem Inst Oswaldo Cruz 99: 239-251.
Silveira FT, Lainson R, De Brito AC, Oliveira MRF, Paes MG, De Souza AAA, Da Silva BM 1997. Leishmaniose tegumentar americana. In RNG Leão, Doenças Infecciosas e Parasitárias: Enfoque Amazônico, CEJUP, Belém, p. 619630.

Silveira FT, Lainson R, Shaw JJ, de Souza AA, Ishikawa EIA, Braga RR 1991. Cutaneous leishmaniasis due to Leishmania (Leishmania) amazonensis in Amazonian Brazil, and the significance of a negative Montenegro skin-test in human infections. Trans $R$ Soc Trop Med Hyg 85: 735-738.

Velasco O, Savarino SJ, Walton BC, Gam AA, Neva FA 1989. Diffuse cutaneous leishmanisis in Mexico. Am J Trop Med Hyg 41: 280-288.

Walton BC, Shaw JJ, Lainson R 1977. Observations on the in vitro cultivation of Leishmania braziliensis. J Parasitol 63: 1118-1119.

Ward RD, Shaw JJ, Lainson R 1978. Hourly activity of Lutzomyia flaviscutellata (Diptera: Psychodidae), a vector of Leishmania mexicana amazonensis. In S Willmott, Medical Entomology Centenary: Symposium Proceedings, R Soc Trop Med Hyg, London, p. 134-135. 